\title{
O Software Régua e Compasso como Facilitador na Aprendizagem Significativa da Geometria Plana
}

\author{
Carmen Angélica Cavalcante do Carmo' ${ }^{1,}$ Delfa Mercedes Huatuco Zuasnábar ${ }^{1}$ \\ ${ }^{1}$ Licenciatura em Informática a Distância -Departamento de Ciência da Computação \\ Universidade Federal de Roraima \\ Av. Capitão Ene Garcez, 2413 - 69310-000 - Boa Vista - RR - Brasil \\ delfa.zuasnabar@ufrr.br, carmenadocarmodyahoo.com.br
}

\begin{abstract}
RESUMO: Este trabalho apresenta o software Régua e Compasso, como forma de dinamizar o processo de ensino e aprendizagem de maneira significativa da Geometria Plana. Utilizou-se como metodologia avaliação escrita para mensurar o conhecimento sobre a geometria plana, exercícios práticos para a interação dos estudantes com o software e questionários aplicados aos estudantes e professor visando avaliar a abstração do conhecimento após sua utilização. Constatou-se que a utilização do software apresenta grande diferencial na construção das figuras geométricas, proporcionando um ambiente de aprendizagem mais interativo, motivador com uma maior participação na construção do seu conhecimento.
\end{abstract}

Palavras Chave: Software Régua e Compasso; Aprendizagem Significativa; Geometria Plana.

ABSTRACT: This study presents the Régua e Compasso software as a way to streamline significantly the process of teaching and learning from Plane Geometry. It was used a written evaluation methodology to measure the knowledge of plane geometry, practical exercises for interaction of students with the software and questionnaires to students and teacher to evaluate abstraction of knowledge after its use. It was found that the use of the software has great difference in the construction of geometric figures, providing a more interactive learning environment, motivator with greater participation in the construction of knowledge.

Keywords: Régua e Compasso Software; Meaningful Learning; Plane Geometry.

\section{INTRODUÇÃO}

As inovações tecnológicas se apresentam hoje cada vez mais avançadas tendo como objetivo maior facilitar a vida das pessoas. Na educação, as novas tecnologias estão provocando mudança na forma de ensinar e de aprender. Essa preocupação em ensinar com novas ferramentas está muito atual, pois é um processo natural com a evolução das novas tecnologias. Desta forma, o ensino da matemática também está associado às inovações tecnológicas através de diversos softwares educacionais que trazem um potencial de aprendizado muito grande para os professores e estudantes [VALENTE, 1993].

Essa tendência tem feito surgir muitos softwares que visam facilitar e motivar a aprendizagem de forma significativa. Na perspectiva de compreender como os alunos 
V Congresso Brasileiro de Informática na Educação (CBIE 2016)

Anais dos Workshops do V Congresso Brasileiro de Informática na Educação (CBIE 2016)

aprendem e, ao mesmo tempo, focalizando-nos em um ensino que traga mais significado para o aluno, consideramos para esta pesquisa, a Teoria da Aprendizagem Significativa [AUSUBEL, 1968].

Dizemos que um indivíduo aprende significativamente quando consegue relacionar, de maneira substantiva (não literal) e não arbitrária, a nova informação com uma estrutura de conhecimento específica que faz parte integrante da sua estrutura cognitiva prévia. [VALADARES, 2011]

A inserção de novos recursos tecnológicos às tradicionais metodologias pedagógicas pode agregar maior valor a uma aprendizagem significativa. Necessitamos internalizar que as tecnologias serão importantes para dar oportunidade a cada pessoa capacitar-se a conduzir o seu próprio modo de aprender, procurando ratificar a aprendizagem até a vida adulta, até o momento em que a escola não fará mais parte de seu processo instrucional. [SCAICO e QUEIROZ, 2013]

Neste trabalho buscou-se analisar de que maneira o software Régua e Compasso pode auxiliar na aprendizagem significativa da geometria plana. Para responder ao questionamento foi apresentado aos alunos e professor o software, destacando suas ferramentas e utilização como forma de dinamizar o ensino e a aprendizagem e relacionar o conteúdo teórico estudado em sala à utilização do software como recurso pedagógico.

Esta pesquisa foi realizada com um grupo de estudantes do $8^{\circ}$ ano do Ensino Fundamental. Buscou-se um objetivo com pluralidade onde os estudantes através da manipulação do Software Régua e Compasso, realizassem atividades associadas ao conhecimento teórico e as práticas desenvolvidas pela interatividade com o software. Assim a pesquisa apresenta o software como proposta metodológica alternativa capaz de instigar e estimular a aprendizagem modificando os conhecimentos prévios e melhorando a abstração dos conhecimentos estudados. E pode contribuir para consolidar os temas já vistos anteriormente.

O trabalho está composto por uma introdução, em que são explícitos os problemas, a justificativa e os objetivos da pesquisa; na segunda seção, abordamos os métodos empregados e suas etapas; na terceira seção, apresentamos os resultados e as discussões das experiências na sala de aula com alunos e professor em que discutimos os dados coletados e as teorias utilizadas na pesquisa. Finalmente na quarta seção apresentamos a conclusão a respeito da pesquisa e as perspectivas sobre sua contribuição para o ensino de Geometria Plana.

\section{MÉTODOS}

Esse estudo teve por finalidade realizar uma pesquisa descritiva, utilizando conhecimentos anteriormente estudados e que melhor trata dos objetivos propostos no trabalho em questão, com o intuito de solucionar problemas. Detectou-se a necessidade da pesquisa bibliográfica porque se fez uso de materiais já elaborados: livros, artigos científicos, revistas, documentos eletrônicos, na busca e alocação de conhecimento sobre o software Régua e Compasso como forma dos professores proporcionarem aos estudantes alternativas dinâmicas de aprendizagem sobre as propriedades de algumas figuras geométricas planas, correlacionando tal conhecimento com abordagens já trabalhadas por outros autores. [FONSECA, 2002] 
A pesquisa foi desenvolvida com quarenta por cento (40\%) do total de alunos desta etapa de ensino, da Escola Estadual Francisco Ricardo Macedo no município de São João da Baliza, Roraima-RR. Para alcançar os objetivos propostos utilizou-se uma metodologia que: Demonstre a dinâmica do software e suas vantagens para a aprendizagem; Incentive o uso do software como recurso visual; Apresente atividades sobre os conteúdos estudados destacando seus conceitos para serem realizadas utilizando o software Régua e Compasso e confronte as atividades propostas com aquelas realizadas em sala utilizando o software.

Foi elaborado um planejamento de quatro etapas de interação com a turma objeto de pesquisa. Na primeira etapa foi aplicada uma avaliação escrita que serviu para saber o conhecimento prévio dos estudantes sobre os assuntos básicos de geometria plana. Na segunda etapa, foi apresentado o software Régua e Compasso mostrando as características, funcionalidades e exemplos práticos.

$\mathrm{Na}$ terceira etapa, foram propostos exercícios para os estudantes interagirem com o software e procurar resolver problemas. Na quarta etapa, foi aplicada uma avaliação, com o objetivo de verificar os conhecimentos adquiridos após o uso do software. Finalmente aplicou-se questionários aos estudantes e ao professor da disciplina de geometria, que possibilitassem obter informações sobre a percepção deles após o uso do software.

\section{RESULTADOS E DISCUSSÃO}

A coleta de dados foi realizada através da aplicação de uma atividade contendo questões referentes aos assuntos estudados durante as aulas práticas sobre a utilização do software Régua e Compasso associados aos conteúdos vistos em sala de aula.

A avaliação demonstrou que a utilização do software Régua e Compasso pelos estudantes tem grande aceitação do recurso como facilitador da aprendizagem. Nas questões que avaliam sua eficiência, cem por cento (100\%) dos estudantes destacaram que os ajudou a perceber com maior clareza as propriedades das figuras trabalhadas e a fixar melhor os assuntos já estudados em sala de aula. Fica evidente diante desse quadro, que mudar a metodologia visando ampliar a compreensão dos estudantes utilizando recursos tecnológicos, é uma alternativa a ser seguida.

Os recursos computacionais podem oferecer de maneira rápida, o
conteúdo necessário para a aprendizagem e estendermos as
abordagens passivas utilizadas para o ensino atual, provendo exemplos
interativos com animações gráficas que ilustrem o funcionamento de
funções, cálculos e construções geométricas, dentre outras áreas.
(ISOTANI, SAHARA e BRANDÃO, 2001)

Ao garantir que a inserção de ferramentas tecnológicas nas aulas de matemática pode-se facilitar o ensino e a aprendizagem, despertar o interesse dos educandos leválos à resolução de problemas com maior facilidade. Sugere-se ao docente se adequar e buscar alternativas que melhorem o aprendizado do aluno e nesse sentido é urgente adquirir conhecimentos sobre os recursos tecnológicos que melhor se adaptam aos conteúdos trabalhados em sala de aula.

Todos os estudantes afirmaram ter compreendido a associação entre teoria estudada e a prática ao utilizarem o software Régua e Compasso. Confirma-se assim a 
importância de propor um ensino que faça sentido, através de situações que os estudantes possam interagir e perceber sua finalidade.

Segundo [MOREIRA e MASINI, 2001] a assimilação é um processo que ocorre quando um conceito ou proposição potencialmente significativa é assimilado sob uma ideia ou conceito mais inclusivo, já existente na estrutura cognitiva. Nesse sentido os referidos conhecimentos adquiridos possibilitaram que os subsunçores originais de cada estudante fossem modificados ao final do processo de assimilação.

Vê-se pois que essa realidade leva a direcionar um ensino contextualizado para que seu significado seja aplicado nas diversas situações do processo de ensino e aprendizagem da matemática.

\section{CONCLUSÃO}

Este trabalho possibilitou uma análise de como a utilização do software Régua e Compasso nas aulas de geometria plana é um instrumento didático de grande potencial porque permite aos alunos à construção das figuras geométricas proporcionando uma visualização plana e espacial, possibilitando a observação e confirmação das propriedades das figuras, permitindo a busca de demonstrações e interação com colegas e professores. Por ser um software simples, dinâmico e de fácil manipulação facilita a compreensão e fixação dos conteúdos da geometria plana, de maneira lúdica tornando a aprendizagem mais significativa e atrativa.

Por fim, a pesquisa apontou que a utilização do software Régua e Compasso sendo utilizado de maneira objetiva, com o rigor que exige o software, os conceitos e propriedades próprias do estudo da geometria plana, é uma alternativa para estimular a criatividade dos estudantes e promover a abstração do conhecimento para aplicá-lo no seu cotidiano.

\section{BIBLIOGRAFIA}

AUSUBEL, D.P. Educational psychology: a cognitive view. New York: Holt, Rinehart and Winston. 1968.

FONSECA, J. J. S. Metodologia da pesquisa científica. Fortaleza: UEC, 2002.

ISOTANI, S.; SAHARA, H. R.; BRANDÃO, O. L. iMática: Ambiente Interativo de Apoio ao Ensino de Matemática via internet. São Paulo: Universidade de São Paulo (USP), 2001.

MOREIRA, M. A.; MASINI, E. F. S. Aprendizagem significativa: A teoria de David Ausubel. São Paulo: Centauro, 2001.

SCAICO, P. D.; QUEIROZ, R. J. G. B. D. A educação do futuro: uma reflexão sobre a aprendizagem na era digital. Revista Brasileira de Informática na Educação, Campinas - SP, 25 a 29 Novembro 2013.

VALADARES, J. A teoria da aprendizagem significativa como teoria construtivista. Aprendizagem Significativa em Revista (ASR), v. 1, p. 36-57, 2011.

VALENTE., J. A. Computadores e conhecimento: repensando a educação. Campinas - SP: Gráfica da UNICAMP, 1993. 